\title{
ANALYSIS OF THE FACTORS AFFECTING UNCERTAINTY IN MEASURING THE GEOMETRY OF DETAILS THROUGH PHOTOGRAMMETRIC METHOD
}

\author{
Georgi Georgiev, Nely Georgieva \\ Trakia University, Faculty of Technics and Technologies \\ Graf Ignatiev 38, 8602 Yambol, Bulgaria \\ e-mail: georgi.georgiev@trakia-uni.bg: nely.georgieva@trakia-uni.bg
}

\begin{abstract}
The accuracy of measurement is determined by measurement errors and uncertainty from the received result caused by accidental impact of various factors. When assessing the uncertainty of contact measurement methods can be used standard procedures, which are missing in non-contact measurements. In this article the determination of the expanded uncertainty at a specific practical case is made in the terms of non-contact measuring of a cylindrical workpiece made of aluminium, which is finely machined. Following the evaluation of the defined input factors first iteration assessment of the expanded uncertainty is made. As a result it was determined that the approximate uncertainty of measurement after the first iteration is greater than target uncertainty. After correction of input variables with the greatest impact the result of the second iteration is satisfying.

Keywords: accuracy of measurement, uncertainty, noncontact measurements.
\end{abstract}

\section{INTRODUCTION}

The result of a measurement differs from the true value of the measured parameter, so that all measurements contain any errors. With investment of time and resources, most sources of measurement errors can be identified, errors can be evaluated and adjusted accordingly, for example by calibration. Rarely, however, there are time and resources to determine and their complete correction.

The presentation of the measurement result by the error of measurement is effective when there is a reference or another source which can present the true value of the measurement with some accuracy, and hence - and opportunity to assess error [2].

In the absence of information about the true value of the magnitude, its assessment in the process of measurement can be accurately determined only by the size of the interval, in which with a certain authenticity can be expected to show the true value - i.e. interval uncertainty of the result.

\section{METHODS}

Uncertainty of measurement is a parameter associated with the measurement result characterizing the dispersion of values that can be attributed to the measurand. It can be defined in various ways. The most widely used and accepted method is Guide to the Expression of Uncertainty in Measurement (GUM), which is presented in the standards [7, 8]. The terminology used is as defined in $[9,10]$.

Under standard [7] uncertainty is defined as "parameter associated with the measurement result characterizing the dispersion of the values that can be reasonably attributed to the measured value". It is presented as a half-length, (positive, negative) next to ascribed value of the magnitude:

\section{value \pm uncertainty (measuring units)}

IRTIIE Vol. 5, No. 1, 2017 ISSN 1314-8788 (print), ISSN 1314-8796 (online), doi: 10.15547/artte.2017.01.001 


\section{ARTIIE

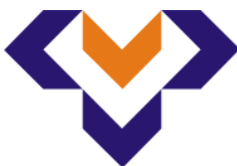

Ipplied Resseirlohes in Technics, Technologies and Bductation

Journal of the Faculty of Technics and Technologies, Trakia University https://sites.google.com/a/trakia-uni.bg/artte/

This is a reasonable interval around the result of the measurement, which is expected to cover the majority of distribution of values that could be attributed to measured value. The difference between the traditional confidence interval and uncertainty is the fact that the latter takes into account the impact of all factors (both internal and external) on the result.

Usually, determining the value of a magnitude $y$ is based on the functional relationship between this value and a set of experimentally determined or known in advance factors (xi), called input variables:

$$
y=f\left(x_{1}, x_{2}, \ldots, x_{n}\right)
$$

These factors have varied character. Figure 1 presents a classification of the possible sources, in accordance with [4].

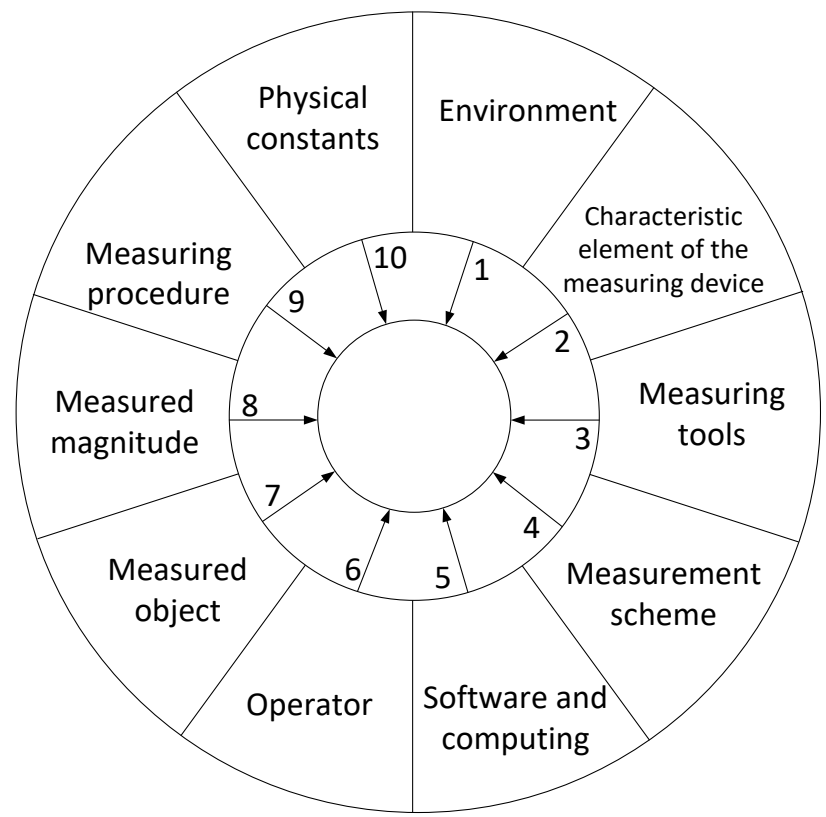

Figure 1. Sources of uncertainty during the measurement

According to the concept of uncertainty each of the factors xi will have its contribution in shaping the general uncertainty of the magnitude $y$. It is accepted constituents components $\mathrm{u}(\mathrm{xi})$ of the expanded uncertainty $\mathrm{U}(\mathrm{y})$, be termed as standard (mean square) uncertainties that inherently have the meaning of standard deviations. Therefore, in order to be assessed general uncertainty in the measurement of the magnitude $y$, must first be defined standard uncertainties of the input variables xi.

The expanded uncertainty $U(y)$, is given by:

$$
\mathrm{U}(\mathrm{y})=\mathrm{k}_{\mathrm{p}} \cdot \mathrm{u}_{\mathrm{c}}\left(\mathrm{x}_{\mathrm{i}}\right)
$$

where $u_{c}\left(x_{i}\right)=\sqrt{\sum_{i=1}^{n} u\left(x_{i}\right)^{2}}$ is the combined mean square indefiniteness in the correlated inputs; $k_{p}$ - factor of cover, which is determined by the confidence level (Table 1, [4]).

The standard uncertainty for its part is divided into two types:

Type $A$ is assessed directly from the analyst through a statistical analysis of a series of observations in terms of repeatability and its quantitative value is the standard deviation of the experimental determination values $x i$.

Some of the variables in the equation (2) can be factors with "known" value and set uncertainty (determined in previous experiments, from the literature, information from the

IRTIIE Vol. 5, No. 1, 2017 ISSN 1314-8788 (print), ISSN 1314-8796 (online), doi: 10.15547/artte.2017.01.001 


\section{ARTTIE $Y$}

Ipplied Resseirl'hes in Teednicis, Technologies and Bductition

Journal of the Faculty of Technics and Technologies, Trakia University https://sites.google.com/a/trakia-uni.bg/artte/

manufacturer). In this case the standard uncertainty is referred to as Type $B$, and it is estimated by methods other than statistical analysis.

For assessment and management of the uncertainty for a measuring process is carried out a procedure whereby the budget uncertainty is defined (Figure.2) [7].

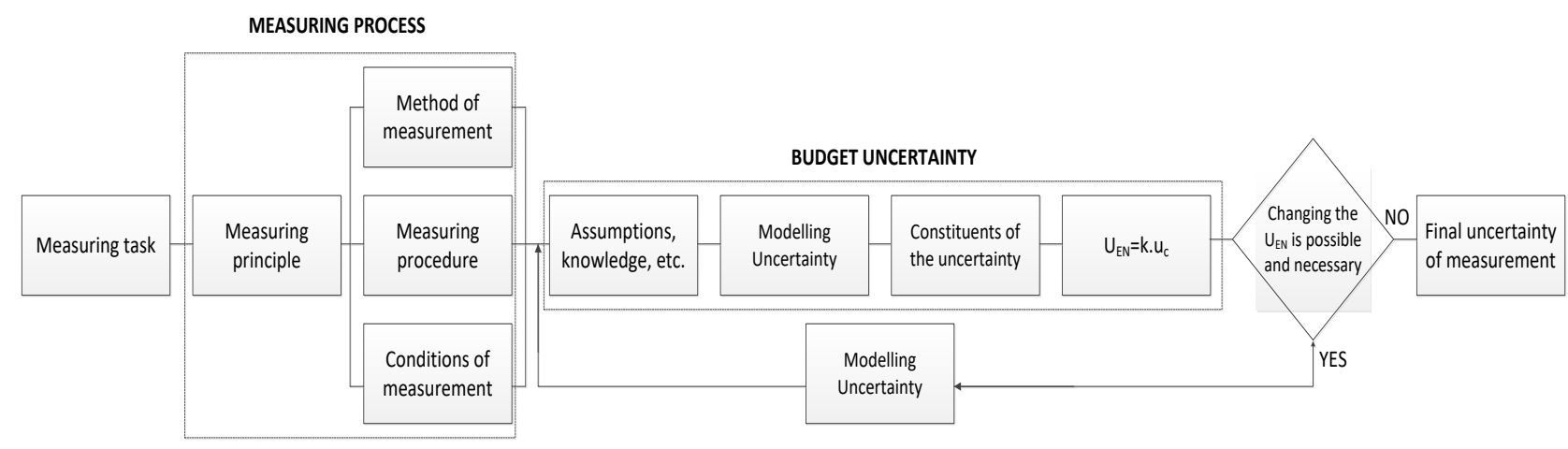

Figure.2. Management of the measurement uncertainty

After creating the budget of the uncertainty of a particular measurement is checked is the inequality fulfilled:

$$
\mathrm{U}_{\mathrm{EN}} \leq \mathrm{U}_{\mathrm{T}} \text {, }
$$

where $U_{E N}$ is the approximate uncertainty of measurement after the $\mathrm{N}$-th iteration; $U_{T}$ - target uncertainty.

When this condition is not fulfilled subsequent iterations are made by executing some of the following actions to satisfy inequality (3):

- It is performed more accurate assessment of the components $\mathrm{x}_{i}$;

- It is changed the method of measurement, the measuring procedure and/or measurement conditions;

- measurement principle;

- It is changed measuring task and/or target uncertainty $U_{T}[1,3]$.

When calculating the uncertainty of measurement by contact methods there are developed methods [5] and software. On the website of the European Association of National Metrology Institutes EURAMET can be found on standard methodologies for estimating uncertainty of a number of specific cases of measurement by contact methods.

After conducted research it was found that when using non-contact methods such methodologies are missed. In [6] there is an attempt to systematize the factors that influence the size of the received measurement uncertainty.

The purpose of this paper is calculating uncertainty of the measurement of geometric parameters of specific detail by photogrammetric method.

\section{EXPERIMENTAL}

An experiment was conducted for measuring diametrical size of the cylindrical workpiece made of aluminium, which is finely machined. Its nominal diameter is measured by contact method with micrometre (range $0-25 \mathrm{~mm}$ ), then it is definitely a deviation from the form roundness by dial gauge with accuracy motion of the sensitive element $0,3 \mathrm{~mm}$ and reading $2 \mu \mathrm{m}$. The obtained dimension was $10.155 \mathrm{~mm}$. Then it was performed verification for deviation of the form in longitudinal section - deviation from cylindricity of the details with the same dial gauge. The obtained dimension was $0.008 \mathrm{~mm}$.

IRTIIE Vol. 5, No. 1, 2017 ISSN 1314-8788 (print), ISSN 1314-8796 (online), doi: 10.15547/artte.2017.01.001 


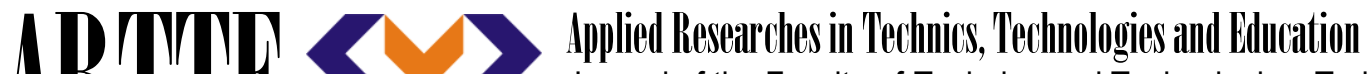 Journal of the Faculty of Technics and Technologies, Trakia University https://sites.google.com/a/trakia-uni.bg/artte/}

For calibration it was used gauge block 10 of the firm „Mitutoyo“, metal, grade $K$ and central deviation $-0,02 \mu \mathrm{m}$, according to the certificate of metrological laboratory.

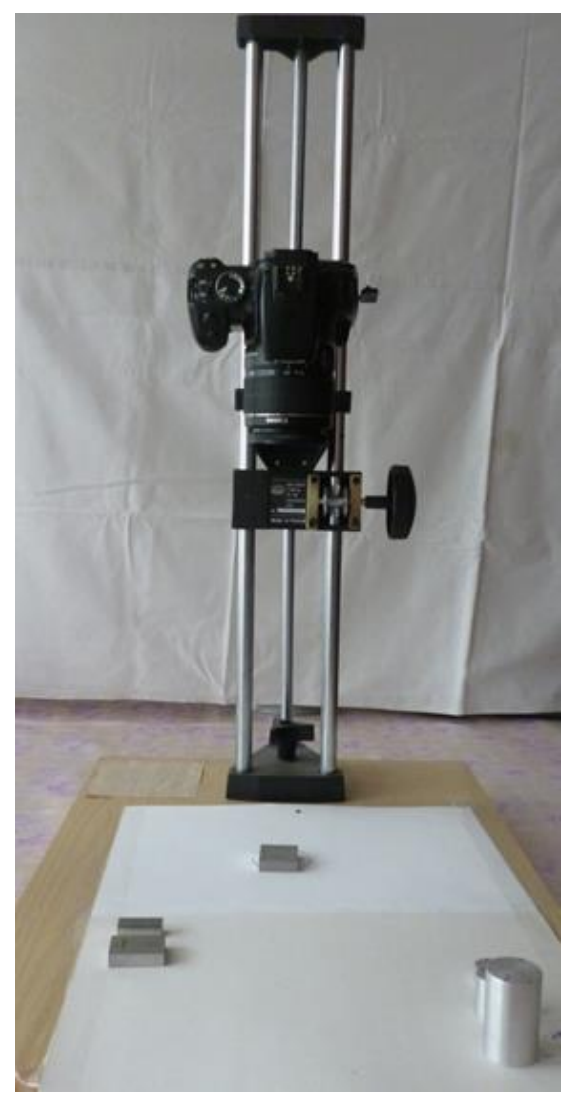

Figure 3.

On Figure 3 is shown used equipment which allows precise mutual orientation in space of shooting equipment and photographed object. For capturing was used a digital camera Canon, model EOS Rebel XTi / 400D, with a matrix Canon APS-C (22,2/ 14,8mm), type CMOS, lens Canon EF50mm 1: 1.8 with a resolution 10,1Mpx (3888 / 2592px).

For photo editing software "Visio 2010" of Microsoft office was used. It was installed on Lenovo V5400 laptop with 15.6-inch screen (diagonal - $39.62 \mathrm{~cm}$ ) 1366x768ppi, matt.

In drawing up budget of Uncertainty and its calculation it was used the sequence of activities described in [4]. Analysis and evaluation of factors input $x i$ is performed. It is accepted that the results should be presented in tabular form. Initially are defined:

\subsection{Task}

The task consists in measuring the diameter of the cylindrical part $D$ through non-contact method photogrammetry, using photographic equipment camera.

\subsection{Target uncertainty}

Equipment for the experiments Target uncertainty $U_{T}=0,01 \mathrm{~mm}$.

\subsection{Principle and method of measurement}

- Principle: measuring length and comparing it to the known length (gauge blocks 10);

- Method of measurement - non-contact, performed on image of the details with accurate reporting $0,001 \mathrm{px}$ and by using software.

\subsection{Measuring procedure}

- Calibration of camera;

- Capture the detail;

- Measuring the size of image;

- Calculation of the expanded uncertainty.

\subsection{Terms at calibration and captures:}

- Constant temperature of $20^{\circ} \mathrm{C} \pm 2^{\circ} \mathrm{C}$ was maintained, used mercuric thermometer had an accuracy of reporting $\pm 1^{\circ} \mathrm{C}$;

- Calibration was accomplished by gauge block 10 - geometric features are known;

- Cylindricity deviation of detail was known - 0,008mm; IRTIIE Vol. 5, No. 1, 2017 ISSN 1314-8788 (print), ISSN 1314-8796 (online), doi: 10.15547/artte.2017.01.001 


\section{ARTIL

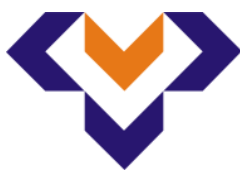 \\ Ipplied Resseirlohes in Technics, Technologies and Bductation \\ Journal of the Faculty of Technics and Technologies, Trakia University https://sites.google.com/a/trakia-uni.bg/artte/}

- Same format of the images was supported-3240x2160px;

- Uniform light calibration and performance capture is maintained;

- Equal values of the distance from the object to the camera matrix $L$ and focal length $f$ are maintained;

- Automatic camera settings are off - auto focus, optical zoom etc.

\subsection{Elements of uncertainty in the measurement of size:}

- Environment - temperature, light;

- A characteristic feature of the measuring device - the photosensitive element of the camera;

- A means of measurement - used software "Visio 2010" takes into account the dimensions accurate to the sixth decimal place, which bears no significant impact;

- Repeatability of experiments - experiments were repeated 45 times, the average mistakes by the operator taking into account is 1,315 pixels;

- Measuring procedure - it is necessary to ensure comparability between the size of detail and caliber;

- Calculations - all calculations are rounded to third significant digit after the decimal point, which bears no significant impact on the evaluated uncertainty.

\section{RESULTS}

Following the evaluation of the defined input factors first iteration assessment of the expanded uncertainty is made. The results are presented in Table 1. In the first column of the table are described input factors $x_{i}$ that influence the process of measuring and contributed to uncertainty. For each parameter are determined mean-square uncertainties that produce common for the procedure. Expanded uncertainty is also calculated.

In that it was found that the inequality (3) is not fulfilled. It was found that the input variables with the greatest impact are: processing of the image during the calibration of the camera, measurement error from the calibration of the camera, the impact of the size of caliber, the impact of the magnitude of the focus $-\mathrm{Kfl}$, processing of the image and measurement error (reporting).

After that it was done correction of input variables with the greatest impact.

The results of the second iteration are shown in Table 2, as the expanded uncertainty after the second iteration of value $U_{E N}=9,126 \mu \mathrm{m}$, satisfying inequality (3).

\section{CONCLUSION}

Based on the survey the following conclusions can be formulated:

- factors that affect the measurement uncertainty of geometrical dimensions by noncontact method - photogrammetry, are identified;

- budget uncertainty of conducted measurement is comprised;

- it was found that the first iteration did not give satisfactory result and was made second iteration;

- it has been shown that in comparison of the resulting uncertainty with that of the contact measuring methods are of the same order of magnitude;

- it was found that the dominant factors on the value of the uncertainty are related to the specifics of the method of measurement. 


\section{Z}

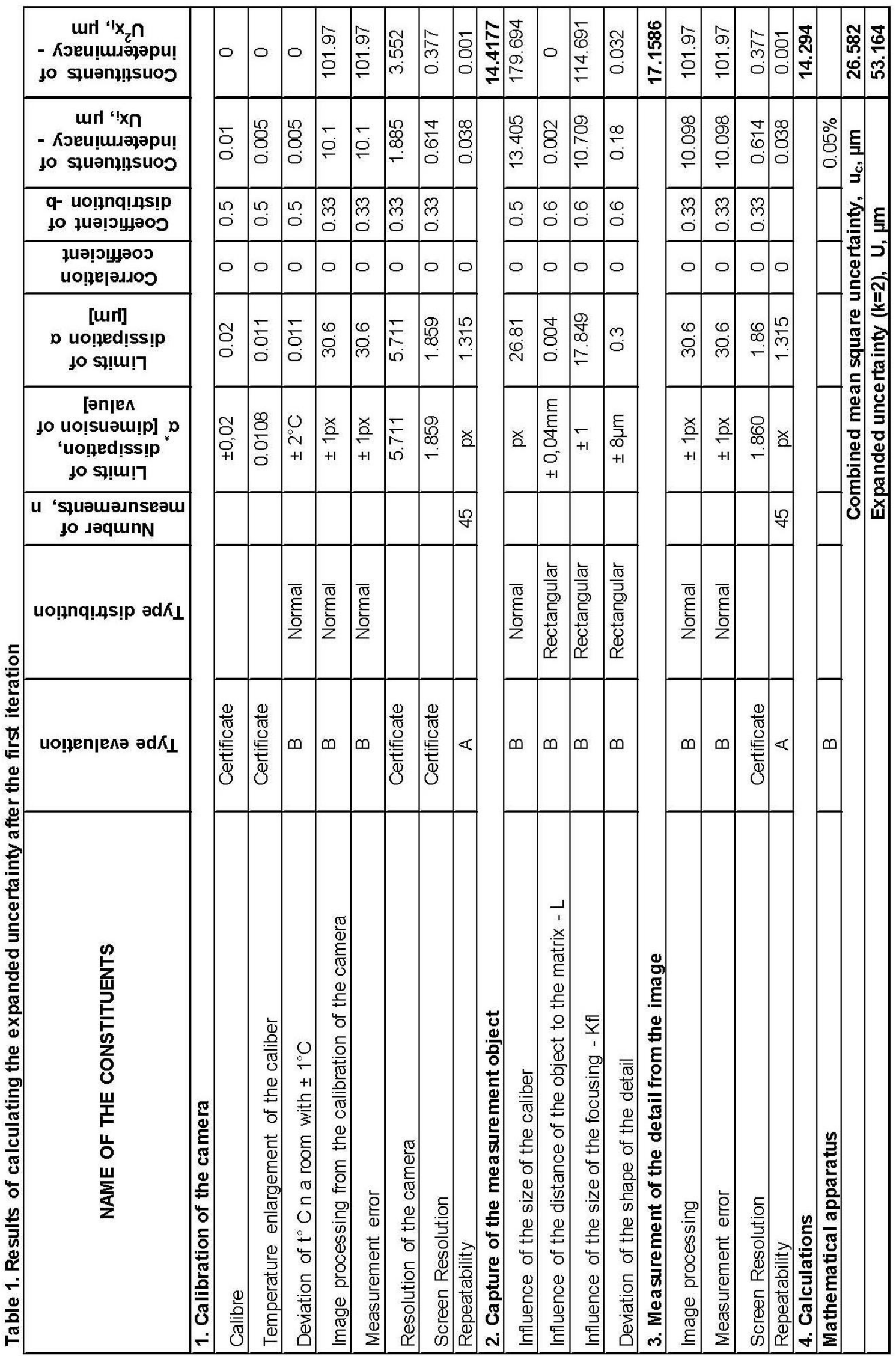




\section{ARTIIE Y}

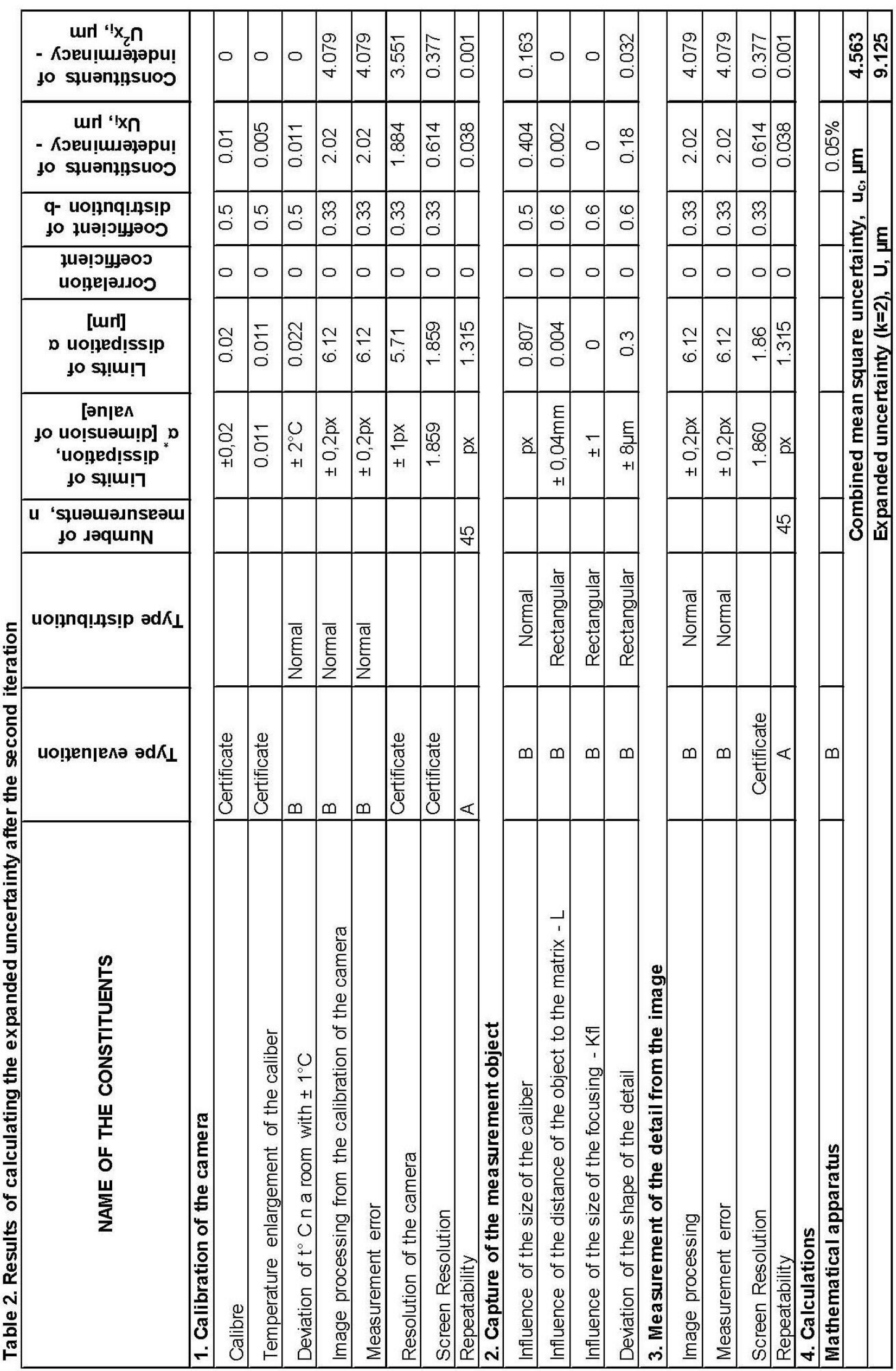

IRTIIE Vol. 5, No. 1, 2017 ISSN 1314-8788 (print), ISSN 1314-8796 (online), doi: 10.15547/artte.2017.01.001 


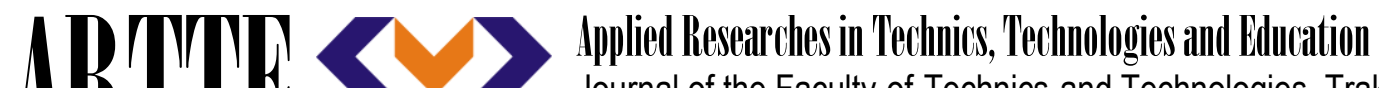 Journal of the Faculty of Technics and Technologies, Trakia University https://sites.google.com/a/trakia-uni.bg/artte/}

\section{REFERENCES}

[1] Keremidchieva, Kr., T. Pehlivanova. Uncertainty and measurement errors - Scientific session "Technology, technology and education", Yambol, 21.12.2001 (in Bulgarian).

[2] Metrology and Measuring Equipment - book-guide in three volumes edited by Hristo Radev, Volume 1, Softrade, Sofia, 2008, ISBN 978-954-334-077-4 (in Bulgarian).

[3] Pehlivanova T., Kr. Keremidchieva Evaluating of measurement uncertainty- Scientific session "Technology, technology and education", Yambol, 21.12.2001 (in Bulgarian).

[4] Radev Hristo, Vasil Bogev uncertainty of the measurement result Softrade, Sofia, 2001, ISBN 954-9725-54-5 (in Bulgarian).

[5] Manual for calibration EURAMET / cg-19 / v.01, booklet 1/2011 (in Bulgarian).

[6] Sakakushev B., C. Grigorov, T. Todorov. Coefficient of performance and analysis of measurement error in photogrammetric method in mechanical engineering. // Magazine. "Proceedings of the Union of Scientists - Rousse", 1/2011. series "Technical Sciences", 2011, issue 5, ISSN 1311-106X. (in Bulgarian).

[7] ISO: Guide to the Expression of Uncertainty in Measurement, First edition 1995, ISBN 92-67-10188-9.

[8] ISO/IEC GUIDE 98-3:2008(E) Uncertainty of measurement - Part 3: Guide to the expression of uncertainty in measurement (GUM:1995).

[9] JCGM 100:2008 Evaluation of measurement data - Guide to the expression of uncertainty in measurement.

[10] JCGM 200:2012 International vocabulary of metrology - Basic and general concepts and associated terms (VIM) 3rd edition. 